\title{
EKSISTENSI BALLA LOMPOA KARAENG MARUSU SEBAGAI WARISAN ARSITEKTUR BUGIS MAKASSAR DI KABUPATEN MAROS
}

\author{
* Andi Asmuliany ${ }^{1}$, Andi Annisa Amalia ${ }^{2}$, \\ ${ }^{1}$ Prodi Perencanaan Wilayah Kota, Fakultas Sains \& Teknologi UIN Alauddin Makassar, Indonesia \\ ${ }^{2}$ Prodi Arsitektur, Fakultas Teknik, Universitas Muhammadiyah Makassar, Indonesia \\ Alamat Email: ayumi_el@ymail.com \\ *Alamat korespondensi, Masuk: 05 Apr. 2019, Direvisi: 04 Mei 2019, Diterima: 29 Mei 2019
}

\begin{abstract}
ABSTRAK: Rumah tradisional Maros merupakan istana Kerajaan Marusu sekaligus kediaman Karaeng Marusu beserta keluarganya merupakan bagian dari sejarah terbentuknya Kabupaten Maros. Rumah adat Balla Lompoa hingga saat ini masih mempertahankan eksistensinya sebagai warisan arsitektur Bugis Makassar dari Kerajaan Marusu yang telah berusia ratusan tahun. Metode penelitian yang digunakan adalah metode pengamatan dan survey lapangan. Hasil penelitian menunjukkan bahwa orientasi bangunan menghadap ke utara dengan pola ruang memanjang ke arah selatan yang terbagi menjadi tiga bagian secara spasial horizontal yaitu Bangunan Inti, Baruga, dan bangunan penunjang. Tipologi bentuk rumah kembar (Bola Kambarae) menyimbolkan kekuasaan lebih dari satu suku dan predikat Andi (Bugis) dan Daeng (Makassar). Selain itu, aktivitas adat berupa upacara ritual diantaranya Appalili, Kattobokko, Appadendang dan Kalula masih dilaksanakan sebagai media untuk menjalin hubungan kekeluargaan dan merupakan produk budaya Kerajaan Adat Marusu.
\end{abstract}

Kata kunci: Warisan arsitektur, Bugis Makassar, tipologi, rumah kembar, upacara adat

\begin{abstract}
Maros traditional house is the palace of the Kingdom of Marusu as well as the residence of Karaeng Marusu and their families is part of the history of the formation of Maros Regency. The traditional house of Balla Lompoa still maintains its existence as an architectural heritage of Bugis Makassar from the Marusu Kingdom which has hundreds of years old. The research method used is the method of observation and field surveys. The results showed that the orientation of the building faces north with a space pattern extending to the south which is divided horizontally into three parts, namely the Core Building, Baruga, and Supporting Buildings. The typology of the twin house form (Bola Kambarae) symbolizes the power of more than one tribe and predicate of Andi (Bugis) and Daeng (Makassar). In addition, traditional activities in the form of ritual ceremonies including Appalili, Kattobokko, Appadendang and Kalula are still carried out as a medium to establish family relations and are a cultural product of the Marusu Customary Kingdom.
\end{abstract}

Keywords: Architectural heritage, typology, twin houses, traditional ceremony.

\section{PENDAHULUAN}

Kerajaan Marusu adalah titik pusaran sejarah islamisasi di Sulawesi Selatan pada awal abad ke-17. Kerajaan Marusu merupakan salah satu kerajaan besar yang dihuni oleh Suku BugisMakassar diidentifikasikan dengan negeri "To Mangkasara" sama halnya dengan Gowa, Takalar, Galesong, Bantaeng, Tope Jawa, Laikang, Binamu dan Bangkala [1]. Adanya hubungan baik antara Kerajaan Gowa Tallo dan Marusu, pada saat Raja Gowa XIV Sultan Alauddin dan Raja Tallo VI Sultan Abdullah Awallul Islam resmi memeluk agama islam, maka agama islam juga resmi menjadi agama Kerajaan Marusu [2].
Pada tahun 1963, Kabupaten Maros terdiri dari 4 kecamatan/distrik yaitu kecamatan Marusu (saat ini disebut Maros Baru), Kecamatan Mandai, Kecamatan Bantimurung dan Kecamatan Camba. Memasuki tahun 1989, diadakan pemekaran wilayah kecamatan dengan terbentuknya 3 (tiga) kecamatan perwakilan, yakni Kecamatan Perwakilan Tanralili, Maros Utara, dan Mallawa, yang hingga saat ini terdapat 14 wilayah kecamatan. Masing-masing wilayah tersebut memiliki potensi tersendiri dalam mendukung perkembangan kabupaten Maros.

Menurut sejarah, rumah adat Balla Lompoa merupakan Istana Kerajaan Marusu yang menandai 
terbentuknya Kabupaten Maros. Rumah tradisional Balla Lompoa Maros berdiri di atas lahan $600 \mathrm{~m}^{2}$ dengan batas-batas sebelah barat adalah Kompleks Makam Kassi Kebo, sisi timur adalah permukiman keluarga istana, sebelah Utara adalah Masjid Kassi Kebo dan sebelah selatan adalah Sungai. Rumah tersebut hingga saat ini merupakan bagian dari kerajaan tertua di Kabupaten Maros Sulawesi Selatan yang pengelolaannya masih menjadi tanggung jawab pihak Keluarga Kerajaan. Sehingga rumah adat ini belum diambil alih oleh pemerintah dan dijadikan sebagai situs budaya atau museum adat seperti pada rumah adat pada umumnya yang ada di Sulawesi Selatan.

Rumah adat Balla Lompoa hingga saat ini masih mempertahankan eksistensinya sebagai warisan arsitektur Kerajaan Marusu yang telah berusia ratusan tahun. Pada zaman kerajaan, bangunan bersejarah Rumah Adat Balla Lompoa yang terletak di Kampung Kassi Kebo dihuni oleh Raja dan Sultan Maros. Istana Kerajaan Marusu pada Masa Pemerintah Hindia Belanda, telah beberapa kali mengalami perpindahan tempat. Awalnya sebelum menempati Kassi Kebo, Istana Kerajaan Marusu bertempat di Pakare, kemudian dipindahkan ke Marusu, lalu ke Pakkasalo dan terakhir di Kassi Kebo [3].

Rumah adat Balla Lompoa Karaeng Marusu merupakan warisan kebudayaan masa lampau yang masih bertahan sebagai simbol kejayaan Kerajaan Marusu masa lalu dan cerminan arsitektur tradisional Bugis Makassar.

Gambar 1. Tata Letak Rumah Adat Balla Lompoa dan Bangunan Penting di sekitarnya

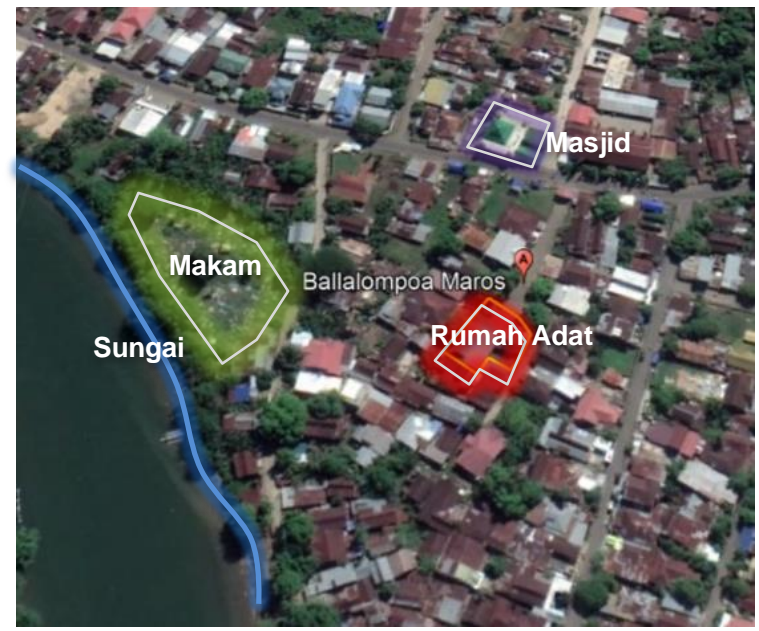

\section{TINJAUAN PUSTAKA}

Arsitektur tradisional merupakan bagian kehidupan masyarakat yang memiliki nilai luhur tinggi yang tidak terlepas dengan tradisi dan nilai filosofis yang melekat bangunan rumah yang didirikan dan terintegrasi dari seluruh "kosmos" atau tata bangunan (arsitektur) [4]. Keberadaan rumah adat dan warisan budaya di Indonesia merupakan simbol dari kebesaran nenek moyang namun biaya perbaikan rumah adat cukup besar sehingga menjadi salah satu faktor penyebab eksistensinya mulai punah [5].

Rumah dalam kebudayaan Melayu Jambi maupun masyarakat pada umumnya di Nusantara sama pentingnya dengan ikatan kekeluargaan yang dipertalikan dengan darah, karena rumah adalah pandangan hidup dan ekspresi, respons dan adaptasi kehidupan dengan lingkungan alam dan sosial [6]. Arsitektur vernakular memiliki konsistensi berupa aturan, bentuk, ornamen, penggunaan bahan dan dimensi yang membutuhkan kesepakatan atau persetujuan dari masyarakat pendukungnya yang didapat melalui proses penerimaan yang dijadikan sebagai tradisi [7].

Rumah Nias adalah potret tradisi Nenek Moyang yang secara rasional menyiasati ancaman sekaligus potensi alam, dimana nilai estetika bangunnya pada logika bahan, konstruksi dan geometri berbentuk sederhana, tidak rumit dan jujur yang penekanan rancangannya pada kebutuhan akan hunian [8]. Rumah Gadang bagi Masyarakat Minangkabau selain sebagai hunian, juga cerminan sistem matrilineal yang dianut serta simbol rasa kebersamaan, kegotongroyongan, demokrasi dan identitas sebuah kaum serta kepenghuluan yang melekat pada kaum tersebut sehingga punya kedudukan berarti dalam kehidupan sosio-kultural masyarakatnya [9]. Lebih lanjut dikatakan bahwa, hampir di seluruh Wilayah Minangkabau, fenomena rumah gadang tradisional bergerak ke arah kepunahan. Padahal ketika rumah gadang sudah rusak dan perlu diperbaiki, tetapi tidak diperbaiki juga, maka kehormatan kaum dengan kepenghuluannya menjadi taruhan, sebab keberadaannya merupakan simbol masyarakat siapa penghulu dari kaum tersebut.

Faktor kondisi alam, masyarakat, serta kepercayaan melandasi konsepsi pembangunan rumah adat Sasak dimana pemilihan bentuk, pengaturan ruang dalam rumah serta penggunaan bahan bangunan berorientasi pada suatu kaidah tertentu yang dianggap suci [10]. Kesetiaan dan konsistensi masyarakat Desa Pakraman Timbrah dalam menjalankan tradisi Bali Aga berbanding terbalik dengan kondisi fisik hunian yang semakin berkurang pekarangan yang memiliki bangunan adat atau sesuai tata ruang, eksistensinya hanya 
pada bangunan sanggah yang tidak mempunyai penyengker terutama pada sisi selatan serta adanya lelompong taksu yang berada pada tembok sisi utara dari bangunan bale atau meten yang posisinya di timur [11].

Arsitektur Bugis Makassar biasanya mengalami transformasi prinsip pada fungsi beberapa ruang, transformasi bentuk denah, transformasi bentuk atap dan transformasi orientasi rumah [12]. Status sosial sangat penting bagi Masyarakat Bugis-Makassar, dimana hal ini ditunjukkan pada penggunaan timpa laja pada fasad bangunan hunian yang diekspresikan dalam bentuk atap datar susun tiga (Timpa laja 'lanta' Tallu) [13].

Pemikiran Masyarakat Bugis Makassar secara totalitas dicerminkan dalam pembuatan rumah tradisional mereka dipengaruhi oleh pemahaman struktur kosmos yang mengacu pada alam atas, alam tengah dan bawah sehingga secara vertikal rumahnya tersusun tiga tingkatan yaitu benua atas, benua tengah dan benua bawah [14]. Rumah adat Bugis tidak hanya unik karena bentuknya, namun karena landasan filosofisnya yakni menggambarkan botting langi (dunia atas), ale kawa (dunia tengah) dan awa bola (dunia bawah), namun terdapat perbedaan bukaan untuk pintu dan jendela pada rumah bugis antar daerah [15].

\section{METODE PENELITIAN}

Metode penelitian yang digunakan adalah metode pengamatan dan survey lapangan, dimana penulis mendapatkan data dari pemilik rumah adat dan juga hasil pengukuran di lapangan. Melakukan pengamatan terhadap keadaan lingkungan objek dan elemen arsitektur. Penelitian ini dilakukan pada bangunan rumah adat Balla Lompoa Karaeng Marusu di Kabupaten Maros Provinsi Sulawesi Selatan. Observasi dilakukan oleh peneliti melalui pengamatan secara langsung untuk mendapatkan data mengenai Eksistensi warisan arsitektur (architectural heritage) pada bangunan Balla Lompoa. Teknik observasi dilakukan agar peneliti memperoleh data yang lebih mendalam mengenai tema penelitian ini. Studi dokumentasi juga dilakukan untuk memperoleh data terkait objek baik dari Badan Pelestarian Cagar Budaya (BPCB) Provinsi Sulawesi Selatan maupun dari instansi terkait di Kabupaten Maros.

\section{HASIL DAN PEMBAHASAN}

\section{Orientasi Bangunan dan Tata Ruang Kawasan}

Istana Balla Lompoa Maros yang lebih dikenal dengan Istana Karaeng Marusu terletak di Kampung Kassi Kebo Kelurahan Baju Bodoa Kebo
Kecamatan Maros Baru Kabupaten Maros. Secara geografis, posisi rumah terletak pada garis lintang $5^{\circ} 0114.93 " \mathrm{~S}$ Latitude dan 119 $34^{\prime} 13.94 " \mathrm{E}$ Longitude. Orientasi bangunan menghadap ke utara dengan pola ruang memanjang ke arah selatan. Kepemilikan asli lahan istana, dulunya cukup luas, hingga saat ini di sekitar istana, didiami oleh keluarga dekat saja, dengan satu akses utama. Bangunan-bangunan inti di sekitar rumah adat antara lain Makam Kassi Kebo, Masjid, dan di bagian Selatan terdapat Sungai sebagai batas fisik sisi Selatan istana Balla Lompoa.

\section{Tata Spasial Horizontal}

Adapun tata spasial horizontal bangunan Balla Lompoa terbagi menjadi tiga bagian yaitu bangunan inti, Baruga, dan Bangunan penunjang. Bangunan inti terdiri dari (1) Bagian depan berupa legolego/teras, (2) Bagian tengah terbagi menjadi dua paddeserang yakni ruang depan utama berupa ruang tamu dan ruang tengah berupa ruang keluarga, (3) Bagian belakang yakni dapur. Bangunan Baruga dihubungkan dengan selasar dari bangunan inti. Bangunan penunjang adalah lumbung padi.

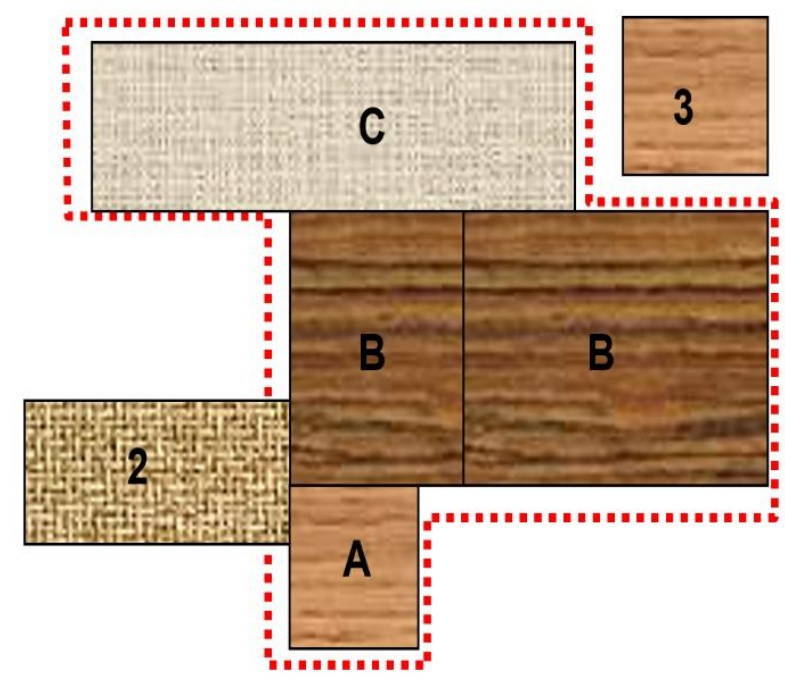

Keterangan :

1. Bangunan inti

a. Bagian depan merupakan teras

b. Bagian tengah terbagi menjadi dua (dua pa'deserang) yakni ruang depan utama dan ruang tengah keluarga

c. Bagian belakang yakni dapur dan ruang makan

2. Baruga

3. Bangunan penunjang yaitu lumbung padi

Gambar 3. Tata Spasial Horizontal Balla Lompoa Maros 


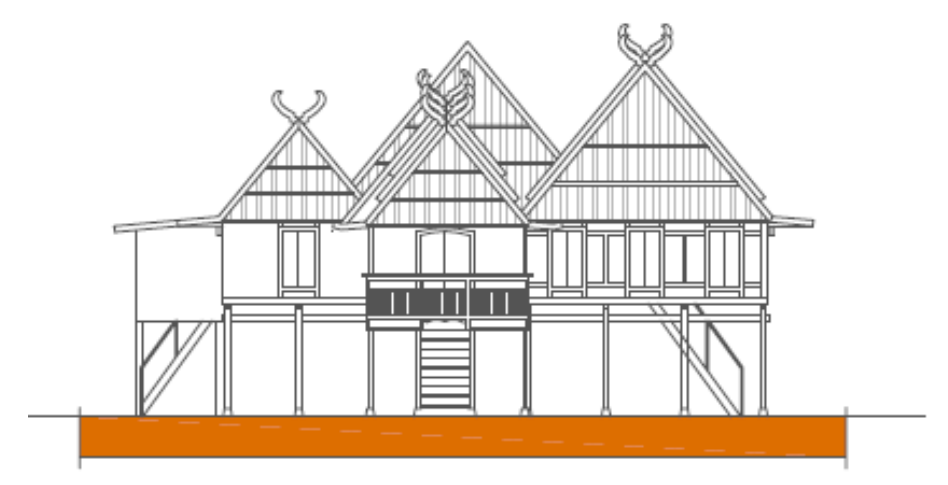

Gambar 4. Tampak Depan Balla Lompoa Maros

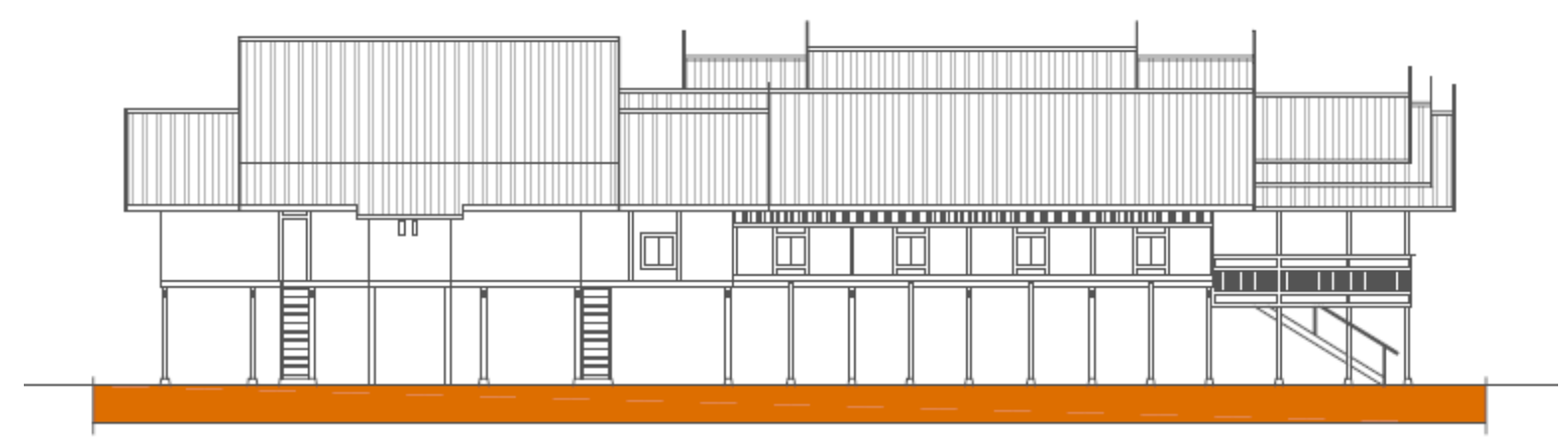

Gambar 5. Tampak Samping Kiri Balla Lompoa Maros

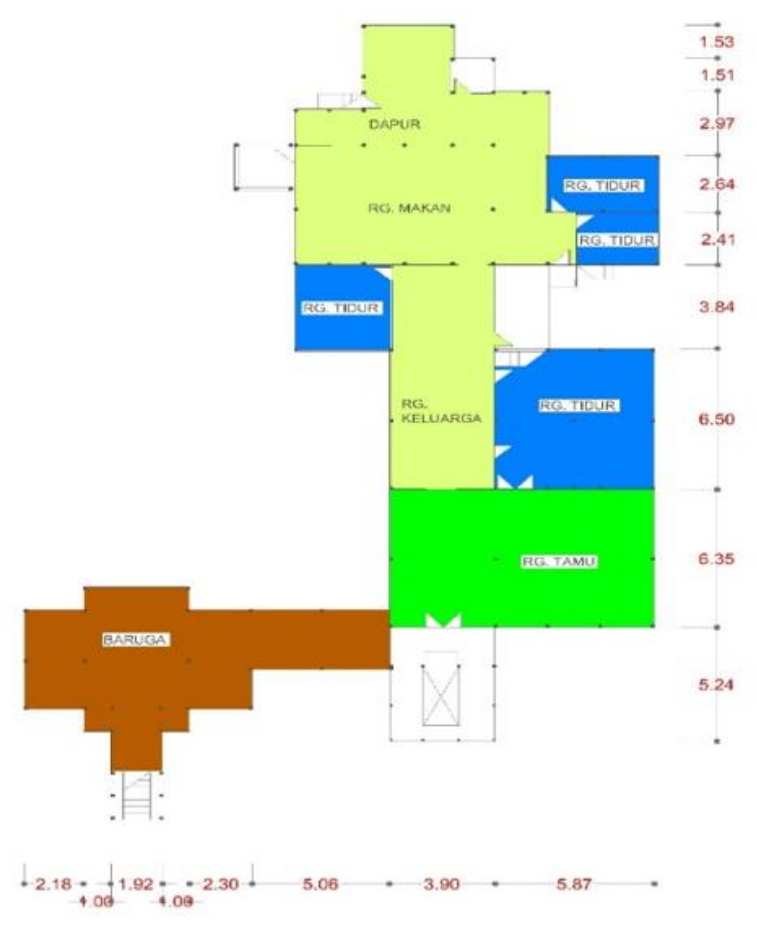

Gambar 6. Denah Rumah Adat Balla Lompoa Maros Sumber : BPCB, 2018 


\section{Bentuk dan Tampilan Bangunan}

Suku Bugis Makassar bisa berbangga karena rumah adat Balla Lompoa Maros yang ada di Kampung Kassi Kebo masih bisa terlihat hingga saat ini. Istilah Balla Lompoa bukan hanya karena bentuk dan ukurannya yang besar, tetapi lebih bermakna pada sifat pemilik rumah hendaknya menjadi pedoman. Itulah juga yang melatar belakangi sehingga tidak ada satupun rumah di sekelilingnya yang boleh membelakangi Balla Lompoa.

Pada umumnya masyarakat Bugis Makassar memiliki keinginan untuk mempertahankan budaya dan adat istiadat tempat mereka berasal dengan mempertahankan bentuk rumah sesuai pakemnya secara turun temurun, namun komposisi serta ukuran bangunan disesuaikan dengan kebutuhan dan kem pemilik rumah [16]. Rumah Balla Lompoa merupakan salah satu rumah adat Bugis Makassar dengan tipologi bentuk rumah kembar (Bola Kambarae). Rumah adat Bugis Makassar dengan tipologi ini hanya ada di tiga kabupaten di Sulawesi Selatan, yaitu di Kabupaten Bantaeng, Kabupaten Bulukumba dan Kabupaten Maros.

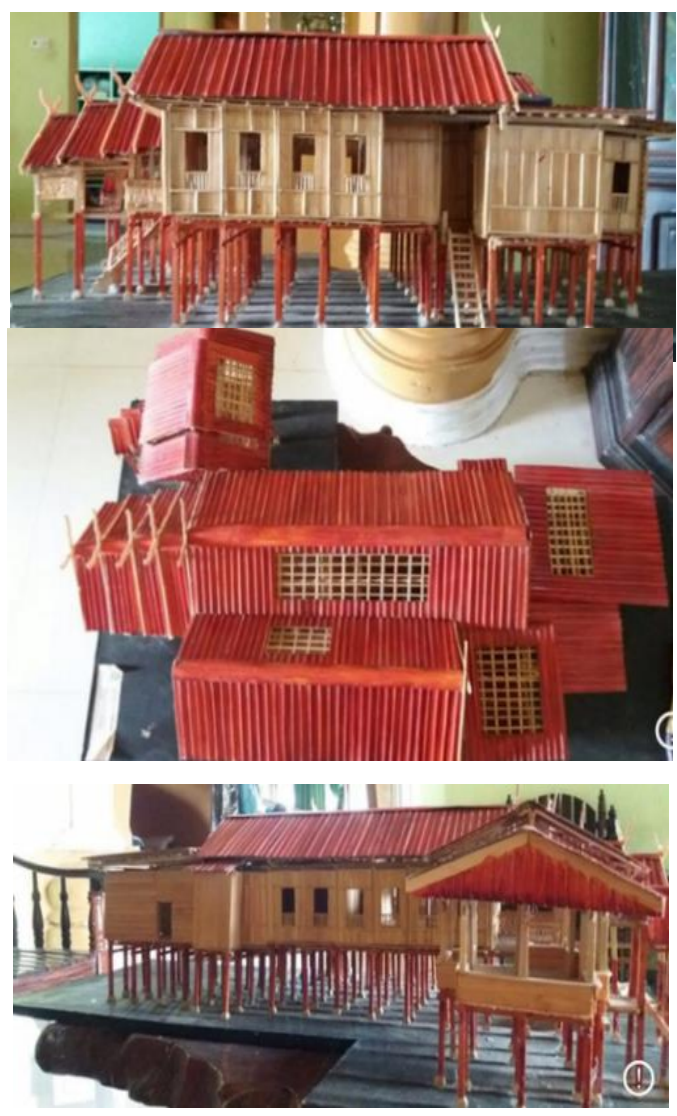

Gambar 7. Maket Rumah Adat Balla Lompoa Maros
Adapun karakteristik bentuk Bola Kambarae Balla Lompoa Maros, yaitu (1) Keberadaan bola kambarae ini tersebar di kabupaten yang merupakan peralihan Suku Bugis-Makassar: (2) Secara historis, dulunya menguasai lebih dari satu suku: (3) Menganut Suku Bugis dan Makassar dimaknai dua kembar artinya bentukan rumahnya berdampingan dan tidak boleh sama baik Panjang maupun lebarnya. Kembar bangunan utama berpredikat Makassar, sedangkan kembar lainnya yang ukurannya lebih kecil berpredikat Bugis: (4) Bentuk badan bangunan yang lebih besar dinamakan Daeng (Makassar) dan yang kecil dinamakan Andi (Bugis).

Bentuk Atap timpa laja bersusun 5 bermakna kekuatan lima kerajaan besar di Kabupaten Maros yakni Maros, Simbang, Tonrolimae, Turikale, dan Tanralili. Selain itu timpalaja ini secara berturutturut dari atas ke bawah yaitu Batara Kale, Batara Tana', Batara Langi' (kemampuan selain diri sendiri untuk saling berbagi) dan Karampoang.

Sedangkan untuk tampilan bangunan fasad hingga saat ini masih mempertahankan warna aslinya yaitu warna merah dan kuning sebagai ciri khas Kerajaan Marusu. Makna pewarnaan tersebut adalah empat unsur sumber kehidupan yaitu tanah, api, air dan angin. Ciri khas penanda untuk warna putih bermakna suci dan netral dimaksudkan untuk pelaksanaan, bahan dan alat harus dijaga kesuciannya (kain putih pada tiang utama rumah/Possi Bola). Sedangkan warna hijau bermakna melancarkan hubungan kemasyarakatan dan simbol islami seperti pada jendela rumah.

Arsitektur tradisional sebagai warisan budaya merupakan pengendapan fenomena dari waktu ke waktu, sehingga perubahan elemen pada arsitektur Bugis Makassar didasari oleh budaya yang melekat dan diwarnai oleh kemampuan perencana, pelaksana dan keinginan pengguna bangunan [17]

\section{Aktivitas Adat}

Aktivitas adat yang masih dilakukan masyarakat berupa upacara ritual yang dilaksanakan sebagai bentuk syukuran atas rezeki yang diberikan dari Allah SWT kepada masyarakat di Kampung Kassi Kebo. Adapun upacara adat yang masih dilaksanakan hingga saat ini adalah Appalili, Kattoboko, Appadendang, dan Kalula.

Upacara budaya Appalili, merupakan upacara yang dilakukan setiap tahun sebelum menggarap sawah. Dulunya upacara ini 
dilakukan pada tanggal dan hari sesuai pendapat dari pattitanrang (pelihat waktu di zaman dulu), namun karena saat ini sudah tidak ada seperti itu sehingga pelaksanaan upacara ditetapkan dan disepakati tanggal 1617 November setiap tahunnya. Tahap pelaksanaan upacara terdiri dari pembenahan, pemeliharaan/pencucian dan pekerjaan membajak sawah. Produk budaya ini turut melambungkan nama Kabupaten Maros sebagai lumbung pangan dan merupakan upacara secara turun-temurun diyakini masyarakat setempat sebagai pedoman bagi petani untuk memulai musim menanam padi [18].

Upacara Kattobokko merupakan pesta panen raya sebagai wujud rasa syukur kehadirat Allah SWT sekaligus sebagai bentuk penghormatan atas keberhasilan hasil pertanian. Upacara ini dilakukan 4 bulan sekali. Jenis padi yang dihasilkan dari sawah yang ada di Kassi Kebo adalah padi tradisional yang kuat, tahan lama dan umurnya panjang. Pada upacara ini, padi yang telah dipanen akan dibagi lagi lalu diikat dengan ikatan tertentu yang disebut bokko atau ikatan padi yang sangat besar. Selain itu pada prosesi jamuan upacara ini kepada para tamu istana Balla Lompoa terdapat 4 jenis beras yaitu beras hitam yang bermakna tanah, beras kuning yang bermakna air, beras merah yang bermakna darah, dan beras putih yang bermakna air.

Upacara Appadendang, merupakan pesta rakyat yang berlangsung di malam hari dengan menumbuk padi yang telah dipanen. Tahapannya terdiri dari tahap accini (menetapkan) setelah dipandang dan memungkinkan untuk dipanen selang waktu 110-135 hari dari pelaksanaan upacara appalili, tahap appasadia (persiapan) berhubungan dengan perlengkapan panen, dan tahap aggau (acara). Ritual dan doa zikir Jumat disebut kalula, diadakan oleh pegawai istana setiap bulan di malam Jumat kecuali pada bulan Muharram dan Bulan Maulid. Pada bulan Muharam dibacakan doa keselamatan yang dilakukan oleh penghuni Balla Lompoa. Sementara pada bulan Maulid merupakan cerita sejarah nabi yang diikuti oleh masyarakat sekitar.

\section{KESIMPULAN DAN SARAN}

Eksistensi Balla Lompoa Maros sebagai warisan budaya Kerajaan Adat Marusu hingga saat ini masih bertahan sebagai (1) Kediaman Karaeng Marusu dan keluarganya, (2) Bola Kambarae yang menyimbolkan kekuasaan lebih dari satu suku dan pemaknaan Andi (Bugis) dan Daeng (Makassar) dan melekat pada masyarakat Sulawesi Selatan, (3) Bentuk atap dan pewarnaan fasad sebagai unsur kehidupan, (4) Upacara adat yang masih dilaksanakan secara turun temurun memberi dampak signifikan pada aspek sosial, agama dan ekonomi khususnya bagi masyarakat di Kampung Kassi Kebo Maros. Oleh karena itu, Rumah adat Balla Lompoa sebagai manifestasi kekayaan budaya merupakan properti dan aset arsitektur Bugis Makassar yang perlu dilestarikan.

\section{DAFTAR PUSTAKA}

[1] Asma, Nur (2015) Maros pada Masa Di/TII 1953-1965. Tesis Universitas Negeri Makassar, Makassar.

[2] Harun (1990) Kerajaan-Kerajaan di Maros dalam Lintas Sejarah. Dekdibud, Maros.

[3] Rachmah (2018) Rumah Adat Balla Lompoa Kakaraengang Marusu Kassi Kebo di Kabupaten Maros (Suatu Kajian Historis). Phinisi Integration Revie: Jurnal Vol. 1, No.1: hal 37-51.

[4] Gambiro H dan Yamin A (2018) Meneropong Istana Tua (Dalam Loka) Warisan Arsitektur Tradisional Sumbawa (Inheritance on Traditional Architecture of Sumbawa). Vitruvian: Jurnal Arsitektur, Bangunan dan Lingkungan Vol. 8, No. 1: hal. 1-10.

[5] Simarmata T dan Sinurat YWB (2015) Eksistensi Warisan Budaya (Cultural Heritage) sebagai Objek Wisata Budaya di Desa Lingga Kabupaten Karo. Anthropos: Jurnal Antropologi Sosial dan Budaya Vol. 1, No.2: hal 148-157.

[6] Anra Y, Sadzali AM (2018) Architecture Varieties of Jambi Malay Traditional House; A Study of Architectural Archeology in Conserving Cultural Heritage and Advancement of Jambi Malai Culture. Titian: Jurnal Ilmu Humaniora Vol. 2, No. 2: hal. 300-322.

[7] Wuisman, JJ (2009) Masa Lalu dalam Masa Kini Arsitektur Indonesia: Posisi dan Peran Tradisi-Tradisi Vernakular Indonesia dan Langgam Bangunan Masa Lalu dan Masa Kini. Jakarta: KITLV Press. 
[8] Nasruddin, Intan FS (2018) Omo Hada: Arsitektur Tradisional Nias Selatan di Ambang Kepunahan. KALPATARU: Majalah Arkeologi, Vol.27, No.2: hal 105-116.

[9] Syafwan (2016) Kebertahanan Rumah Gadang dan Perubahan Sosial di Wilayah Budaya Alam Surambi Sungai Pagu, Kabupaten Sosok Selatan. Humanis: Jurnal Ilmiah Ilmu-Ilmu Humaniora, Vo.XV, No.1: hal 105-119.

[10] Sukawi dan Zulfikri (2010) Adaptasi Arsitektur Sasak terhadap Kondisi Iklim Lingkungan Tropis. BERKALA TEKNIK: Jurnal Universitas Diponegoro Vol. 1. No.6: hal 339-346.

[11] Swanendri NM (2016) Eksistensi Tradisi Bali Aga pada Arsitektur Rumah Tinggal di Desa Pakraman Timbah. Ruang: Jurusan Arsitektur Fakultas Teknik Universitas Udayana, Vol. 3, No.2: hal 145-156.

[12] Nurhuzna A (2017) Transformasi Fungsi dan Bentuk Arsitektur Bugis-Makassar di Pesisir Pantai Buti Merauke. Jurnal Ilmiah Mustek Anim Ha, Vol. 6, No. 2: hal 193-203.

[13] Hidayat R, et.al. (2013) The Expression of Social Status on House Form (Case: Bugis-Makassar Modern House). International Journal of Scientific \& Engineering Research, Vol. 4, Issue 3: pp. 1-5.

[14] Raodah (2012) Balla Lompoa di Gowa (Kajian Arsitektur Tradisional Makassar). Patanjala, Vol. 4, No.3: hal 378-390.

[15] Marwati, Andriani S (2017) Tipologi Bukaan pada Rumah Tradisional Bugis di Benteng Somba Opu Makassar. Nature: Jurnal Teknik Arsitektur UIN Alauddin Makassar, Vol. 4, No.2: hal 107-120.

[16] Octavia S, Hematang Y (2017) Adaptasi Bentuk dan Fungsi Arsitektur Rumah Tradisional Bugis-Makassar di Kampung Kumbe, Merauke. Jurnal Ilmiah Mustek Anim Ha, Vol. 6, No. 3: hal 286-298.

[17] Rahmansah, Rauf B (2014) Arsitektur Tradisional Bugis Makassar (Survei pada Atap Bangunan Kantor di Kota Makassar). Jurnal Forum Bangunan, Vol. 12, No.2: hal 56-63.

[18] Nurhalimah (2018) Tradisi Appalili di Kassikebo Kecamatan Maros Baru Kabupaten Maros (2005-2017). Tesis Program Pascasarjana Universitas Negeri Makassar. 